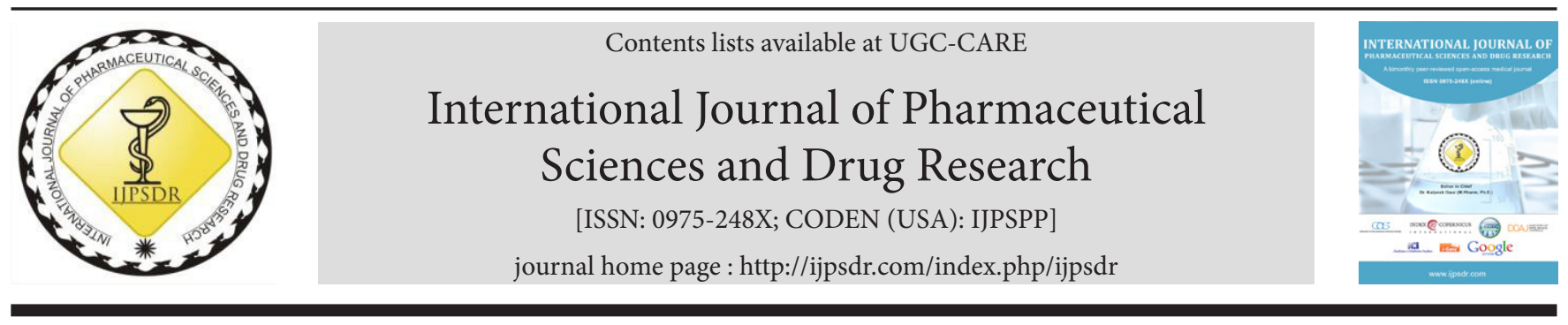

Research Article

\title{
Fourier Transform Infrared and Chromatographic Fingerprint of Essential Oil from Pogostemon benghalensis (Burm. F.) Kuntze
}

\author{
Pradeep Damodaran Premakumari ${ }^{1 *}$, Manoj Gopal Sarayu ${ }^{1}$, Murugan Kumaraswamy ${ }^{2}$ \\ ${ }^{1}$ Department of Botany, Mahatma Gandhi College, Trivandrum-695004, Kerala, India \\ ${ }^{2}$ Center for Innovation in Science and Social Action, Trivandrum-695014, Kerala, India
}

\begin{tabular}{l} 
A R T I C L E I N F O \\
\hline Article history: \\
Received: 03 May, 2020 \\
Revised: 29 July, 2020 \\
Accepted: 15 August, 2020 \\
Published: 30 September, 2020 \\
Keywords: \\
Essential oil, \\
Fourier transformed infrared \\
spectroscopy (FTIR), \\
Functional groups, \\
Gas Chromatography and Mass \\
Spectroscopy (GC-MS), \\
High-performance thin-layer \\
chromatography (HPTLC), \\
Pogostemon. \\
D0I: \\
10.25004/IJPSDR.2020.120508
\end{tabular}

\section{INTRODUCTION}

Biomedical, environmental, and food industry demands chemical analysis of components directly or indirectly used or consumed by human beings. Modern analytical tasks consist of rapid screening of a wide series of pharmaceutical and food samples for a plausible forgery or contamination. In the chemical evaluation of biological samples, one difficulty is the unpredictability of their chemical composition of a given herbal extract, plus the issue of the costs of authentic phytochemical standards.

\begin{abstract}
A B S T R A C T
The purpose of the present research work is to investigate the functional group and category of secondary metabolites present in the essential oil (Eo) from Pogostemon benghalensis, using Fourier transform infrared (FTIR) spectrometry, high-performance thin-layer chromatography (HPTLC), and gas chromatography and mass spectrometry (GC-MS) technique. FTIR measures the vibrations of bonds within the functional groups and yields a spectrum that can be considered as a biochemical or metabolic fingerprint of the plant product. Using FTIR spectra, it is possible to find out the minor changes of primary and secondary metabolic characteristic functional groups, which are responsible for their biological feature of the species. FTIR is a non-destructive, cost-effective, user-, and eco-friendly tool. P. benghalensis, a wild relative of Pogostemon cablin, the highly utilized and adulterated medicinal herb by the native people for the extraction of essential oil patchouli. The fresh leaves were subjected to hydro-distillation for the extraction of the essential oils and were analyzed using the above techniques. The FTIR spectral lines have shown diverse, unique peaks of functional groups. FTIR confirmed the volatile compounds and indicated by their functional groups of the essential oils, such as, C-H (alkene), C-H (aromatic), and C=C. Similarly, the analysis proved the presence of alcohol, p-substituted alcohols or phenols, alkanes, alkynes, alkenes, aldehyde, ester, ether, aliphatic amines, carboxylic acids, aromatics, ketones, disulfide, alkyl halides, halogen, and nitro derivatives. The intensity and estimation of predominant volatiles were analyzed by HPTLC, which showed eight peaks with max Rf values ranged from 0.07 to 0.96 . Further, the Eo was fractionated by with GC-MS technique and identified 41 volatile fractions in the oil. Thus, the obtained data provides the biochemical profiles with overlapping signals of a wide array of molecules that are present in the cells. So, the usage of essential oils in pharmacy, cosmetology, and aromatherapy industries may be substantiated. Further advanced spectroscopic analysis is required to identify the structure and nature of active principles present in the Eo.
\end{abstract}

\footnotetext{
${ }^{*}$ Corresponding Author: D. Pradeep Damodaran Premakumari

Address: Research Scholar, Department of Botany, Mahatma Gandhi College, Trivandrum-695004, Kerala, India

Email $\bowtie$ : prempradeep358@gmail.com

Tel.: +91-9447321405

Relevant conflicts of interest/financial disclosures: The authors declare that the research was conducted in the absence of any commercial or financial relationships that could be construed as a potential conflict of interest.

Copyright (C) 2020 Pradeep Damodaran Premakumari et al. This is an open access article distributed under the terms of the Creative Commons Attribution- NonCommercial-ShareAlike 4.0 International License which allows others to remix, tweak, and build upon the work non-commercially, as long as the author is credited and the new creations are licensed under the identical terms.
}

Traded herbal products are mostly available in a dried and crumbled or powdered form. FTIR, HPTLC, and GC-MS instrumental systems can provide valuable information for chemotaxonomic analyses of similarities and dissimilarities among individual species. The system must feature efficient fingerprinting of herbal products with the detection system ensuring partial yet immediate identification. A remarkable feature of chromatography is that it can even be used for the separation of the volatile fractions (like terpenes) when employed at the 
lowest temperatures $\left(-20\right.$ or $\left.-10^{\circ} \mathrm{C}\right)$ and using silica gel as a strong enough adsorbent. ${ }^{[1]}$ In many studies, researchers successfully tested this possibility upon the essential oils (Eos) derived from many aromatic species belonging to Lamiaceae. Eos is secondary metabolites that are known for their fragrance and flavor features. They consist of a mixture of mono and sesquiterpenes, phenylpropanoids, and oxygenated molecules. Eos are localized in different plant parts and regions, and their storage is related to specialized secretory structures. ${ }^{[2]}$ Therapeutically, the Eos exert many activities, like antiseptic, stimulant, carminative, diuretic, anthelmintic, analgesic, anti-rheumatic, aromatic, counterirritant, and many other activities. Apart from food and pharmaceutical applications, they are also used as insect repellents, insecticides, pesticides, and deodorants. FTIR spectroscopic tool, a simple, cost-effective, and ecofriendly tool employed to analyze functional groups and structural hydrocarbon of phyto-molecules in medicinal species. FTIR spectroscopic tool gets popularized and expanding in research fields due to its non-destructive analysis of biological samples. ${ }^{[3]}$ The major focus of the tool is diagnosis of a molecule via spectral images. The present study aims to characterize the essential oil from P. benghalensis, using FTIR, HPTLC, and GC-MS techniques leading to the identification of functional groups and individual components present.

\section{MATERIAL AND Methods}

\section{Plant Material}

Fresh leaves of $P$. benghalensis were used in the present study and were collected from the natural habitats of Munnar Hills of Idukki district, Kerala, India, in July 2019. The collected species were identified using flora and were authenticated at the herbarium of Jawaharlal Nehru Tropical Botanic Garden and Research Institute (JNTBGRI), Palode, Trivandrum, Kerala, India. The voucher specimens were numbered (MGH 1456) and kept in the herbarium of the Department of Botany, M. G. College, Trivandrum, Kerala, India. The collected plants were washed thoroughly with running tap water, air-dried and ground to a coarse powder, and stored in air-tight bottles at $4^{\circ} \mathrm{C}$.

\section{Extraction of Eo}

Volatile oil (Eo) was extracted from the fresh leaves of $P$. benghalensis by the process of steam distillation in a Clevenger-type apparatus. The fresh leaves were cut into small pieces for the maximum extraction of oil and placed in a round bottom flask connected to the apparatus. The system was operated continuously for 5 hours for the maximum yield. Water was used as an extraction solvent. Since the oil is immiscible and lighter than water, it is formed as a separate upper layer in the measuring tube. The Eo collected in the measuring tube is carefully separated out and stored in amber-colored glass bottles.
Water is removed using anhydrous $\mathrm{Na}_{2} \mathrm{SO}_{4}$ and stored at $4^{\circ} \mathrm{C}$ for further experimental studies. ${ }^{[4]}$

\section{FTIR Analysis}

Absorption spectra were measured in the 500 to $4,000 \mathrm{~cm}^{-1}$ domain, using an FTIR technique, model FTIR 640, and JASCO product. This measuring technique has the advantage of a signal/noise ratio, particularly advantageous. For this reason, a full spectrum measuring time is reduced. The high measuring speed (under a second) enables repeated measurements (the device was set for 64 consecutive measurements), following to calculate the average for each value of the wavenumber (operation acquisition of spectra). Due to the measurements of 64 spectra, the signal/noise ratio improved eight times. Samples of essential oil and essential oil used as a reference were compressed in the form of thinfilm (about $20 \mu \mathrm{m}$ ) between two slides of calcium fluoride crystal (transparent between 500-4,000 $\mathrm{cm}^{-1}$ ) and interposed in the optical path of the radiation source with infrared emission. ${ }^{[5]}$ Fourier transform spectrophotometer operation is based on light interference and a mathematical transformation (Fourier transform) of the detector signal, which obtains the absorption spectrum of the sample and reference material. ${ }^{[6]}$

\section{HPTLC Analysis}

The major compounds present in the Eo of Pogostemon were estimated using an HPTLC system (CAMAG, Switzerland) connected with the Linomat $\mathrm{V}$ sample applicator and CAMAG twin-trough plate development chamber. CAMAG TLC scanner 3 and WinCATS software 4.0 were used for the identification of peaks in the HPTLC system. Silica gel plates (60F-254, Merck, Germany, $20 \times 10 \mathrm{~cm}$, $0.2 \mathrm{~mm}$ thickness) as stationary phase, and mixture chloroform: ethyl acetate $(8: 2)(\%, v / v)$ as mobile phase was used to produce a sharp, symmetrical, and wellresolved peak. The present mobile phase composition was developed after testing different solvent systems of varying polarities. The Eo was applied to the silica gel HPTLC plates, using an automatic Linomat V sample applicator, fitted with a Camag microsyringe in $\mathrm{N}_{2}$ flow (application rate-150 $\mathrm{nL} / \mathrm{s}$, space between two bands $-11 \mathrm{~mm}$, slit dimension- $6 \times 0.45 \mathrm{~mm}$, scanning speed-20 mm/sec) under saturated conditions (30 minutes). These plates were scanned densitometrically at $366 \mathrm{~nm}$ (Hg lamp, K 400 optical cut-off filter), using TLC Scanner 3, and the data were analyzed with WinCATS Software 4.03. ${ }^{[7]}$

\section{GC-MS Analysis}

The GC-MS analysis was carried out on a HewlettPackard 6890 gas chromatograph (Agilent Technologies, USA). $1 \mu \mathrm{L}$ of Eo was injected into the equipment for the identification of volatile fraction present in the oil. The equipment was fitted with 30 metre $(\mathrm{m}) \times 0.32 \mathrm{~mm}$ i.d., and $0.25 \mu \mathrm{m}$ film thicknesses Hp-5 capillary column 
coupled with a model 5973 mass detector. GC-MS operation conditions: carrier gas: helium $(1.4 \mathrm{~mL} / \mathrm{min})$; injection mode: split $\left(1: 1\right.$ ratio, v/v); injector temperature: $220^{\circ} \mathrm{C}$; detector temperature: $250^{\circ} \mathrm{C}$; transfer line temperature: 60 to $246^{\circ} \mathrm{C}\left(3^{\circ} \mathrm{C} / \mathrm{min}\right)$; mass spectra electron impact $\left(\mathrm{EI}^{+}\right)$ mode, $70 \mathrm{eV}$; ion source temperature: $240^{\circ} \mathrm{C} .{ }^{[8]}$

\section{RESULTS AND DiscusSion}

\section{Essential Oil}

Essential oils are a mixture of volatile, aromatic, and hydrophobic constituents, mainly comprise of terpenes and their derivatives. Eos is extracted from the leaf, flower, seed, twig, wood pulp, or bark tissues of higher plants. These oils are very interesting natural products are used in aromatherapy, pharmacology, pharmaceutical, chemical, and food industries and possess various biological activities. The most common method for extraction of Eos is hydro-distillation, and the volatiles present in the oil are identified using different chromatographic techniques. A 300 grams of $P$. benghalensis fresh leaves yielded $1.15 \mathrm{~mL}$, $0.383 \%(\mathrm{v} / \mathrm{w}$ ) brownish-yellow colored oil with clear, transparent, and characteristic medicinal aroma.

\section{FTIR Spectroscopy of Eos}

Fig. 1 represents the absorption spectrum of essential oil obtained from $P$. benghalensis recorded in the wavelength range 4,000 to $500 \mathrm{~cm}^{-1}$, with a resolution of $4 \mathrm{~cm}^{-1}$. Each spectrum has been derived as a result of the accumulation of 64 individual spectra. Vegetal samples were gathered from the area Trei Ape-Garana and Arboretum Park Bazos. The 1,400 to $400 \mathrm{~cm}^{-1}$ peaks region denotes the infrared (IR) spectral fingerprint, which contains the absorption bands that characterize the molecules' entire molecular structure through vibrations of the spectrum, deformation, and combining, harmonic bands that cannot be usually be attributed by normal vibrations. Fingerprint zones can be employed to discriminate the structure by comparing it with the IR spectrum of a standard molecule. If the two compared spectra (the

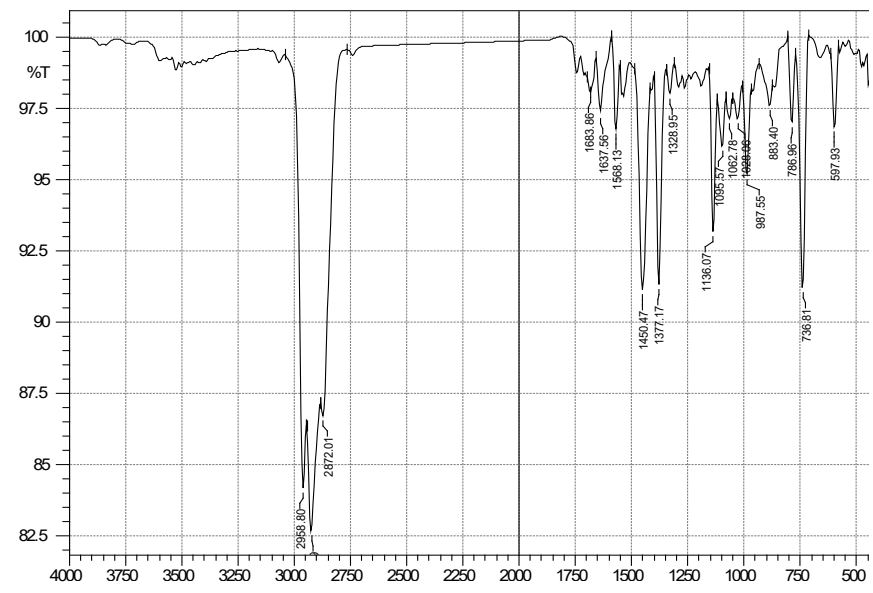

Fig. 1: FTIR spectrum of essential oils from P. benghalensis sample and the standard molecule) has similar absorption in the fingerprint region, it is strongly confirmed as compared to other methods (e.g., comparing the melting points or thin-layer chromatograms) that the structure of the compound to be analyzed is the same as that of the standard, but the IR spectra must be measured in the same conditions. In the charged peaks of the absorption, bands can be spotted by intense absorptions due to the deformation vibrations of the $\mathrm{C}-\mathrm{H}$ bond and the valence vibrations of $\mathrm{C}-\mathrm{O}$ single bonds of alcohols, ethers, esters, and the C-halogen bonds. ${ }^{[9]}$

The IR spectrum is an ideal tool for providing molecular structural information. $P$. benghalensis Eos spectrum revealed the peaks at $1,683.86$ to 597.93 and $2,958.8$ to $2,872.01 \mathrm{~cm}^{-1}$ range. In the high wavelength range, alkane functional class stretching vibrations were showed by the peaks at $2,958.8$ and $2,925.91 \mathrm{~cm}^{-1}$, whereas the band at $2,872.01 \mathrm{~cm}^{-1}$ was assigned to the $\mathrm{C}=0$ stretch stretching vibrations of the terpenoids group. The peak at $1,328.95,1,136.07,1,095.57,1,062.78,1,028.86$, and $736.81 \mathrm{~cm}^{-1}$ indicated the presence of alcohol and phenols functional groups. The peak at $786.96 \mathrm{~cm}^{-1}$ confirms the presence of arene group assigned with $\mathrm{C}-\mathrm{H}$ (bending and ring puckering). The remaining peak at 1,683.86 and $1,637.56 \mathrm{~cm}^{-1}$ indicated the presence of alkene. $1,450.47$ and $1,377.17 \mathrm{~cm}^{-1}$ indicated the alkane bending vibrations of $\mathrm{CH}_{2}$ and $\mathrm{CH}_{3}$ deformation. The IR bands were dominated by alkynes, $\mathrm{C}-\mathrm{H}$ deformation stretching vibration at $597.93 \mathrm{~cm}^{-1}$. The $\mathrm{C}-\mathrm{H}$ and $\mathrm{CH}_{2}$ bending vibrations were seen at 987.55 and $833.4 \mathrm{~cm}^{-1}$, whereas the $\mathrm{O}-\mathrm{H}$ bending vibrations were displayed at $736.81 \mathrm{~cm}^{-1}$ with alcohol and phenols functional class (Table 1).

The presence of salient absorption bands for functional groups can be validated by structural assignments but should not be based solely on absorptions seated in this area because they are most often applied only for substantiating the proposed structure by taking into account the characteristic group absorptions in other regions of the spectrum. The $\mathrm{H}_{2}$ bonds change the vibration frequencies of the Eos that possess $\mathrm{O}-\mathrm{H}$ and $\mathrm{N}-\mathrm{H}$ bonds. The absorption band's position due to $\mathrm{O}-\mathrm{H}$ bonds valence vibration is employed to justify the association strength through $\mathrm{H}_{2}$ bonding. When the association through $\mathrm{H}_{2}$ bonding is stronger, the $\mathrm{O}-\mathrm{H}$ bond length enhances, and bond force constant reduces, so the valence vibration is discriminated at lower frequency values as compared to the values identified in the absence of association with $\mathrm{H}_{2}$ bonds. The vibration absorption band given by the free $\mathrm{O}-\mathrm{H}$ bond valence occurs in the region of 3,590 to $3,650 \mathrm{~cm}^{-1}$, and the association through polymer $\mathrm{H}_{2}$ bonds leads to wide bands in the region 3,200 to $3,600 \mathrm{~cm}^{-1}(\mathrm{COOH}$ broadband absorption from low frequencies, in 2,500$3,000 \mathrm{~cm}^{-1}$ domain, due to associations of strong dimers).

The destruction of the intermolecular $\mathrm{H}_{2}$ bonds by diluting with a solvent not participating in $\mathrm{H}_{2}$ bonding (non- 
FTIR and GC fingerprint of Eo from P. benghalensis

Table 1: FTIR interpretation of compounds of Eo of $P$. benghalensis

\begin{tabular}{|c|c|c|c|}
\hline Range $\left(\mathrm{cm}^{-1}\right)$ & Functional class & Intensity & Assignment \\
\hline $2,958.8$ & Alkane & Strong & $\mathrm{CH}_{3}, \mathrm{CH}_{2}$, and $\mathrm{CH}$ ( 2 or 3 bands) \\
\hline $2,925.91$ & Alkane & Strong & $\mathrm{CH}_{3}, \mathrm{CH}_{2}$, and $\mathrm{CH}$ ( 2 or 3 bands) \\
\hline $2,872.01$ & Terpenoids & Medium-strong & $\mathrm{C}=0$ stretch \\
\hline $\begin{array}{l}1,683.86 \\
1,637.56\end{array}$ & Alkene & $\begin{array}{l}\text { Weak, broad } \\
\text { O-H stretching }\end{array}$ & $\mathrm{C}=\mathrm{O}$ (symmetric reduces intensity) \\
\hline $1,568.13$ & Arene & Medium-weak & $\mathrm{C}=\mathrm{C}$ (in ring, 2 band: 3 , if conjugated) \\
\hline $\begin{array}{l}1,450.47 \\
1,377.17\end{array}$ & Alkane & Medium & $\mathrm{CH}_{2}$ and $\mathrm{CH}_{3}$ deformation \\
\hline $\begin{array}{l}1,328.95 \\
1,136.07\end{array}$ & & & \\
\hline $\begin{array}{l}1,095.57 \\
1,062.78 \\
1,028.86\end{array}$ & Alcohol and phenols & Strong & Usually broad C-O \\
\hline 987.55 & Alkenes & Strong & $=\mathrm{C}-\mathrm{H}$ \\
\hline 833.4 & Alkenes & Medium & $=\mathrm{CH}_{2}$ (out of plane bending) \\
\hline 786.96 & Arene & Strong-medium & C-H (bending and ring puckering) \\
\hline 736.81 & Alcohol and phenols & Weak & $\mathrm{O}-\mathrm{H}$ bending \\
\hline 597.93 & Alkynes & Strong & C-H deformation \\
\hline
\end{tabular}

polar organic solvent) results in the reduction of the polymer band intensity and the occurrence of a narrow band range seated at higher frequencies, characteristic to the valence vibration of the $\mathrm{O}-\mathrm{H}$ free bond (unassociated), so it reflects that the Eos absorption spectra of different species varied substantially. ${ }^{[10]}$ To represent the similarity between the spectra of the two products, the spectra in question are digitized, represented as a set of pairs of values (wavelength number vs. transmission\%). Each spectrum consists of 3,113 such pairs of values. A comparison of the two spectra from biosystems, which are to be denoted quantitatively for similarity, is a comparison of the absorbance values for each pair of values of the 3,113 wavenumbers vs. transmission\%. In the case of the theoretical identity of the two spectra, for each value of the wavenumber, the transmission linked with the two spectra should be equal. ${ }^{[1]}$

Samfira et al. ${ }^{[6]}$ analyzed IR spectral features of lavender, peppermint, green Douglas, and chicory Eos. The correlation coefficient values for the oils derived from mint, green Douglas fir, and chicory were lesser than 0.97 , the value calculated for lavender. Elzey et al. ${ }^{[12]}$ documented the FTIR spectrum of the pure Eos oflemon, revealed the characteristic C-H stretch $\left(\sim 2,900 \mathrm{~cm}^{-1}\right), \mathrm{C}=0$ stretch $\left(\sim 1,700 \mathrm{~cm}^{-1}\right)$, broad 0 -H stretch $\left(\sim 3,400 \mathrm{~cm}^{-1}\right)$, and C-O stretch $\left(\sim 1,100 \mathrm{~cm}^{-1}\right)$ of terpenoid fractions. The compositions and constituents of Eos may vary and depend on the soil environment. In general, Eos is made up of terpenes, like terpineol, cineole, citronellal, and others. Boughendjioua and Djeddi ${ }^{[13]}$ also noticed similar results from the lemon Eo of Algeria.
Luca et al. ${ }^{[14]}$ used analytical and preparative tools to identify the various coumarins. Tangpao et al. ${ }^{[15]}$ compared aromatic profiles of essential oils from five commonly used at Thai Basils. Foudah et al. ${ }^{[16]}$ developed a modified HPTLC validated method for the simultaneous quantification of eucalyptol and $\alpha$-pinene in Lamiaceae species. Sahayaraja et al. ${ }^{[17]}$ screened phytochemicals by FTIR spectroscopic analysis of leaf and stem extracts of Wedelia biflora. Tahir and Abbasi ${ }^{[18]}$ validated Mentha spicata extracts by FTIR spectroscopic analysis. Elzey et al. ${ }^{[12]}$ proved the purity of adulterated essential oils by FTIR spectroscopy and partial-least-squares regression techniques. Morar et al. ${ }^{[19]}$ characterized the essential oils extracted from different aromatic plants by FTIR spectroscopy. Adinew ${ }^{[5]}$ studied GC-MS and FTIR analysis of essential oil from Cinnamon bark growing in the south-west of Ethiopia. Samfira et al. ${ }^{[6]}$ characterized, identified, and confirmed the Eos by midinfrared absorption spectrophotometry.

\section{HPTLC Analysis}

To analyze the major compounds present in the Eos, HPTLC analysis was carried out. The HPTLC analysis showed eight peaks from $P$. benghalensis. The max Rf values of Eo from $P$. benghalensis ranged between 0.07 to 0.96 , and area $\%$ were between 2.29 and 33.61. The fractions' maximum height ranged from 26.1 to 185.4 , which indirectly indicates the oil's presence of major components (Table 2). Geethika and Sunojkumar ${ }^{[20]}$ carried the HPTLC fingerprint profile of Leucas stelligera, Leucas eriostoma, and Leucas ciliate. 
Pradeep Damodaran Premakumari et al.

Table 2: HPTLC profile of Eo from P. benghalensis

\begin{tabular}{llllllllll}
\hline Peak & Start $R f$ & Start height & Max Rf & Max height & Max\% & End Rf & End height & Area & Area\% \\
\hline 1 & 0.04 & 79.1 & 0.07 & 105.6 & 21.4 & 0.08 & 1 & 927.5 & 6.98 \\
2 & 0.12 & 0.3 & 0.17 & 45.7 & 6.17 & 0.18 & 13.9 & $1,001.2$ & 4.01 \\
3 & 0.19 & 2.3 & 0.25 & 28.6 & 5.26 & 0.26 & 12.8 & 501.2 & 2.29 \\
4 & 0.26 & 9.1 & 0.29 & 26.1 & 3.45 & 0.31 & 3.7 & 547.3 & 2.54 \\
5 & 0.33 & 0.5 & 0.38 & 27.1 & 3.94 & 0.38 & 4.1 & 521.8 & 2.41 \\
6 & 0.38 & 0.5 & 0.43 & 32.7 & 3.89 & 0.43 & 0.8 & 510.7 & 2.32 \\
7 & 0.76 & 5.9 & 0.84 & 185.4 & 23.4 & 0.89 & 2.6 & $7,240.1$ & 33.61 \\
8 & 0.93 & 43.1 & 0.97 & 67.5 & 10.2 & 0.97 & 1.5 & 569.4 & 2.84 \\
\hline
\end{tabular}

The Rf values ranged between 0.06 and 0.98 for the species. The fingerprint analysis gives the idea for the authentication of the herbal extracts and its constituents and provides the parameters for the quality of herbal formulations. Gomathi et al. ${ }^{[21]}$ effectively discriminated compounds by HPTLC fingerprinting analysis of Evolvulus alsinoides. Iwin et al. ${ }^{[22]}$ reported HPTLC analysis of the alkaloid profile of stem bark extracts of Terminalia chebula. Vinatha et al. ${ }^{[23]}$ screened the phytochemicals by HPTLC fingerprint analysis of leaf extract from Bridelia montana. Bobby et al. ${ }^{[24]}$ analyzed the crude powder and dry ethanolic extracts of Albizia lebbeck leaves by FTIR and recorded alcohols, phenols, alkanes, carboxylic acids, aromatics, ketones, and alkyl halides compounds corresponding to the peaks at $3,370.19,2,955.65$, 2,925.68, 2,853.4, 1,739.72, 1,463.02, and $506.57 \mathrm{~cm}^{-1}$, respectively. Similarly, Thangarajan et al. ${ }^{[25]}$ analyzed and documented the compounds in Ichnocarpus frutescens. Rao et al. ${ }^{[26]}$ carried HPTLC analysis of the essential oil from Pimenta dioica leaf extracts.

The methanol extract of Limonia acidissima fruit contained alcohols, phenols, alkanes, amino acids, $\alpha, \beta$-unsaturated esters, alkenes, nitro compounds, aromatics, aliphatic amines, carboxylic acid, alkenes, and alkyl halides compounds, ${ }^{[27]}$ while the ethanolic extract of Ipomoea obscura showed the presence of most of the secondary metabolites in the plant leaves. ${ }^{[28]}$ Similarly, Cayratia trifolia plant stem ethanolic extract holds more phytochemicals and bioactive compounds that were confirmed using FTIR. ${ }^{[29]}$ Jayashree and Ramesh ${ }^{[30]}$ analyzed the methanolic extract of fruit pulp of Feronia limonia and documented the presence of a phenolic, aromatic, and aliphatic functional group.

\section{GC-MS Analysis}

GC-MS was a reliable tool used to identify and quantify the volatile compounds present in the Eos with the help of peak area, retention time, and comparison with authentic known standards in the library. In the present study, the essential leaf oils from $P$. benghalensis revealed 41 volatile compounds representing $97.43 \%$ of the total oil. The oil contained mainly terpenoids and its derivatives, viz., monoterpene hydrocarbons, oxygenated monoterpenes, sesquiterpene hydrocarbons, oxygenated sesquiterpenes, and other compounds (Table 3). The major fraction of Eo of P. benghalensis was oxygenated sesquiterpenes (48.41\%), followed by sesquiterpene hydrocarbons (35.31\%), oxygenated monoterpene $(9.61 \%)$, monoterpene hydrocarbons $(3.5 \%)$, and other volatiles $(0.65 \%)$. The major compound identified from the GC-MS chromatogram of P. benghalensis was $\alpha$-cadinol comprised $35.78 \%$ of the oil.

In addition to the major compounds, 1,8 cineole (7.14\%), aromadendrene $(4.16 \%)$, p-cymene $(1.6 \%)$, bornyl acetae $(2.15 \%)$, longicyclene $(2.74 \%), \beta$-elemene $(1.56 \%)$, longifolene $(1.18 \%), \alpha$-caryophyllene $(1.08 \%)$, $\beta$-caryophyllene $(1.14 \%)$, trans- $\beta$-farnesene $(1.56 \%)$, $\alpha$-patchoulene $(2.39 \%)$, gurjunene $(2.86 \%)$, valencene $(2.21 \%)$, epi-cubedol (1.03\%), bicyclogermacrene $(2.78 \%)$, trans- $\beta$-guaiene $(1.26 \%)$, $\alpha$-bisabolene $(1.16 \%), d$-cadinene $(2.45 \%)$, elemol (1.01\%), spathulenol (1.16\%), caryophyllene oxide (1.15\%), guaiol (1.79\%), isolongifol (1.20\%), cubenol1-epi $(1.56 \%), \alpha$-murolol (1.45\%), bulsenol (1.51\%), and cadalene-8,9-epoxide $(2.95 \%)$ were identified as remarkable fractions of Eo of $P$. benghalensis.

Total volatile products of Mentha piperita leaves were $58.61 \%$, as revealed by the GC-MS analysis, and the yield was $1.02 \%$. Thirty volatile compounds were identified and the major constituent in the leaf was menthone (29.01\%), followed by menthol (5.58\%), menthyl acetate (3.34\%), menthofuran $(3.01 \%), 1$, 8-cineole (2.40\%), isomenthone (2.12\%), limonene (2.10\%), $\alpha$-pinene (1.56\%), germacrene-D (1.50\%), $\beta$-pinene $(1.25 \%)$, sabinene $(1.13 \%)$, and pulegone $(1.12 \%) .{ }^{[31]}$ The investigation on the Eo of Leucas virgata led to the identification of 43 constituents, comprising $93.9 \%$ of the total oil. The Eos of L. virgata was characterized by a high content of oxygenated monoterpenes (50.8\%), followed by oxygenated sesquiterpenes (21\%). Camphor (20.5\%), $\beta$-eudesmol (6.1\%), caryophyllene oxide $(5.1 \%)$ exofenchol (3.4\%), fenchon (5.4\%), and borneol (3.1\%) were identified as the main components. ${ }^{[32]}$

The chemical composition of the hydro-distilled essential oil from the flowering aerial parts of Leucas indica indicated the presence of fifty-six 
Table 3: GC-MS profile of $P$. benghalensis

\begin{tabular}{|c|c|c|c|c|}
\hline No. & Compound & LRI (Cal.) & LRI (Lit.) & P. benghalensis \\
\hline 1 & $\alpha$-pinene & 925 & 932 & 0.42 \\
\hline 2 & Camphene & 935 & 946 & 0.18 \\
\hline 3 & $\alpha$-terpene & 1,018 & 1,014 & 0.89 \\
\hline 4 & p-cymene & 1,021 & 1,020 & 1.6 \\
\hline 5 & 1,8-cineole & 1,026 & 1,026 & 7.14 \\
\hline 6 & $\gamma$-terpinene & 1,054 & 1,054 & 0.41 \\
\hline 7 & Linalool & 1,095 & 1,095 & 0.32 \\
\hline 8 & Bornylacetae & 1,288 & 1,287 & 2.15 \\
\hline 9 & d-elemene & 1,336 & 1,335 & 0.53 \\
\hline 10 & Longicyclene & 1,373 & 1,371 & 2.74 \\
\hline 11 & $\beta$-elemene & 1,386 & 1,389 & 1.56 \\
\hline 12 & $\beta$-longipinene & 1,395 & 1,400 & 0.98 \\
\hline 13 & Longifolene & 1,402 & 1,407 & 1.18 \\
\hline 14 & $\alpha$-caryophyllene & 1,403 & 1,408 & 1.08 \\
\hline 15 & $\beta$-caryophyllene & 1,414 & 1,417 & 1.14 \\
\hline 16 & Aromadendrene & 1,437 & 1,439 & 4.16 \\
\hline 17 & Trans- $\beta$-farnesene & 1,452 & 1,454 & 1.56 \\
\hline 18 & $\alpha$-patchoulene & 1,456 & 1,454 & 2.39 \\
\hline 19 & Alloaromadendre & 1,460 & 1,458 & 0.76 \\
\hline 20 & Gurjunene & 1,473 & 1,475 & 2.86 \\
\hline 21 & Valencene & 1,496 & 1,491 & 2.21 \\
\hline 22 & Epicubedol & 1,489 & 1,493 & 1.03 \\
\hline 23 & Bicyclogermacrene & 1,498 & 1,500 & 2.78 \\
\hline 24 & Trans b guaiene & 1,500 & 1,502 & 1.26 \\
\hline 25 & $\beta$-bisabolene & 1,507 & 1,505 & 1.16 \\
\hline 26 & $\alpha$-bulnesene & 1,508 & 1,509 & 0.47 \\
\hline 27 & d- cadinene & 1,524 & 1,522 & 2.45 \\
\hline 28 & Elemol & 1,542 & 1,548 & 1.01 \\
\hline 29 & Germacrene B & 1,550 & 1,559 & 0.84 \\
\hline 30 & Spathulenol & 1,570 & 1,577 & 1.16 \\
\hline 31 & Caryophyllene oxide & 1,577 & 1,582 & 1.15 \\
\hline 32 & Guaiol & 1,594 & 1,600 & 1.79 \\
\hline 33 & Isolongifol & 1,615 & 1,618 & 1.2 \\
\hline 34 & Cubenol-1-epi & 1,618 & 1,627 & 1.56 \\
\hline 35 & Epi- $\alpha$--cadinol & 1,632 & 1,638 & 0.38 \\
\hline 36 & $\alpha$-murolol & 1,635 & 1,644 & 1.45 \\
\hline 37 & $\alpha$-cadinol & 1,656 & 1,652 & 35.78 \\
\hline 38 & Allohimachalol & 1,670 & 1,661 & 0.64 \\
\hline 39 & Bulsenol & 1,672 & 1,670 & 1.51 \\
\hline 40 & Cadalene 8,9 epoxide & 1,681 & 1,675 & 2.95 \\
\hline 41 & Isoamycinnamate & 1,732 & 1,740 & 0.6 \\
\hline & \multicolumn{3}{|c|}{ Monoterpene hydrocarbon } & 3.5 \\
\hline & \multicolumn{3}{|c|}{ Oxygenated monoterpene } & 9.61 \\
\hline & \multicolumn{3}{|c|}{ Sesquiterpene hydrocarbon } & 35.31 \\
\hline & \multicolumn{3}{|c|}{ Oxygenated sesquiterpene } & 48.41 \\
\hline & \multicolumn{3}{|l|}{ Others } & 0.6 \\
\hline & \multicolumn{3}{|l|}{ Total } & 97.43 \\
\hline
\end{tabular}

compounds with $71.8 \%$ sesquiterpene hydrocarbons. The other components were $\beta$-caryophyllene (51.1\%) and $\alpha$-caryophyllene $(10.2 \%) .{ }^{[33]}$ GC-MS result of Thymus capitatus Eo comprised of 22 components. Thymol (51.22\%), carvacrol (12.59\%), and $\gamma$-terpinene $(10.3 \%)$ were identified as the major components, i.e., $74.11 \%$ of the total composition of the oil. ${ }^{[34]}$ The essential oil of Salvia officinalis seeds showed a higher percentage of oxygenated monoterpenes $(50.14 \%)$ than sesquiterpenes (17.32\%), followed by monoterpenes $(5.93 \%)$ in the GC-MS profile. Further, caryophyllene oxide $(7.28 \%), 13$-epi-manool (5.61\%), $\delta$-elemene (3.97\%), and $\beta$-eudesmol $(3.76 \%)$ were identified as the major fraction. $^{[35]}$

The GC-MS analysis of Rosmarinus officinalis oil collected from different loci dominated by $\alpha$-pinene (13.5$37.7 \%)$, 1,8-cineole (16.1-29.3\%), verbenone (0.8-16.9\%), borneol (2.1-6.9\%), camphor (0.7-7\%), and racemic limonene $(1.6-4.4 \%) .{ }^{[36]}$ Kariminik et al. ${ }^{[37]}$ studied the essential oil composition of the four medicinal plants from the Lamiaceae, including Salvia macrosiphon, $R$. officinalis, Dracocephalum polychaetum, and Origanum vulgare. S. macrosiphon, $R$. officinalis, D. polychaetum, and $O$. vulgare represented 11, 14, 5, and 20 compounds, respectively, in the GC-MS analysis. Linalool (54.8\%) and manool (27.3\%) were the principal components of $S$. macrosiphon, while $\alpha$-pinene (15.5\%), verbenone (14.3\%), 1, 8-cineole (12.4\%), camphor (11.9\%), bornyl acetate (7.9\%), borneol (6.5\%), and camphene (5.8\%) were the major components in R. officinalis. Cyclo geranate (69.9\%) and limonene (19.9\%) were revealed as the main components of D. polychaetum Eo, and other components were present only as trace amounts. O. vulgare, GC-MS analysis indicated the presence of thymol (27.4\%), $\gamma$-terpinene $(12.1 \%)$, terpinene-4-ol (11.6\%), transsabinene hydrate (5.9\%), and trans-anethole (3.6\%). The composition of Eos in the above-published data of other species of Lamiaceae showed the remarkable difference when compared with the present study.

A rapid, simple, accurate, and specific FTIR, HPTLC, and GC-MS method were carried in P. benghalensis. The results of the present study showed the presence of alkanes, alkenes, alkynes, arene, alcohols, aromatics, terpenoids, and phenols as the major fractions. The chromatographic investigation of Eo of $P$. benghalensis revealed the presence of 41 compounds. The data could be used as a quality control standard. The method resulted in good peak shape and enabled good resolution from the constituents of the essential oils. The presence of various bioactive compounds present in the Eo justifies its importance in the pharmaceutical industry. The present study revealed the ecological and economic significance of Eo from plants as a prospective for possible application in different medicinal, cosmetic, and food products based on further investigations, such as, isolation of the individual phytochemical constituents and their efficacies. 
Pradeep Damodaran Premakumari et al.

\section{CONCLUSION}

The present study indicated that the spectra obtained from the essential oil of $P$. benghalensis correspond to the presence or absence of a wide variety of functional groups in a molecule. The GC-MS analysis of the essential oil revealed that the chemical composition was characterized by high content of oxygenated sesquiterpenes (48.41\%) followed by sesquiterpenes hydrocarbons (35.31\%). $\alpha$-cadinol, 1, 8-cineole, aromadendrene were identified as the main components. The chromatographic fingerprints supports the essential oil from $P$. benghalensis can be utilized for the manufacture of perfumery products, as well as, in the pharmaceutical industry.

\section{ACKNOWLEDGMENT}

The authors acknowledge the Director of JNTBGRI for providing facilities for the GC-MS analysis of Eos and herbaria reference for the proper identification of the species.

\section{REFERENCES}

1. Shaha A, Salunkhe VR. Development and Validation of A high performance thin layer chromatographic method for determination of 1,8-cineole in callistemon citrinus. Pharmacognosy Res. 2014; 6(2):143-147.

2. Sourestani mm, Piri E, Mottaghipisheh J, Vitalini S, Iriti M. monthly Changes in Contents and Compositions of Oil of Callistemon citrinus: A Comparison Study. Nat Prod Res. 2020; 21:1-7.

3. Le Borgne E, Cicchetti E, Bertrand T. HPTLC methods for qualitative and quantitative analysis of selected furocoumarins in essential oils. Flavour and Fragrance Journal. 2017 Sep;32(5):330-339.

4. Essien EP, Essien JP, Ita BN, Ebong GA. Physicochemical Properties and Fungitoxicity of the Essential Oil of Citrus Medica L. against Groundnut Storage Fungi. Turk J Bot. 2008; 32: 161-164.

5. Adinew B. GC-MS and FT-IR Analysis of Constituents of Essential oil from Cinnamon Bark Growing in South-west of Ethiopia. Int J Herb Med. 2014;1(6):22-31

6. Samfira I, Rodinob S, Petrachec P, Cristina RT, Butu M, Butnariu M. Characterization and Identity Confirmation of Essential oils by Mid Infrared Absorption Spectrophotometry. Dig J Nanomater Bios. 2015;10(2):557-566.

7. Rajana R, Varghese SC, Kurupa R, Gopalakrishnan R, Venkataramand R, Satheeshkumar K, Baby S. Search for Camptothecin Yielding Ophiorrhiza species from Southern Western Ghats in India: A HPTLC-densitometry Study. Ind Crops Prod. 2013;43: 472-476.

8. Raj G, Pradeep DP, Yusufali C, Dan M, Baby S. Chemical Profiles of Volatiles in Four Alpinia species from Kerala, South India. J Essent Oil Res. 2013;25(2):97-102.

9. Ouedraogo IW, Boulvin M, Flammang R, Gerbaux P. Conversion of Natural Aldehydes from Eucalyptus citriodora, Cymbopogon citratus and Lippia multiflora into Oximes: GC-MS and FT-IR Analysis. molecules. 2009;14(9):3275-3285.

10. Petrache P, Rodino S, Butu M, Pribac G, Pentea M, Butnariu M. Polyacetylene and Carotenes from Petroselinum sativum root. Dig J Nanomat Bios. 2014;9(4):1523-1527.

11. Butu M., Rodino S, Pentea M, Negrea A, Petrache P, Butnariu M. Screening of Bioflavonoid and Antioxidant Activity of Lens culinaris Medikus. Dig J Nanomat Bios. 2014;9(2):519-529.

12. Elzey B, Norman V, Stephenson J, Pollard D, Fakayode SO. Purity Analysis of Adulterated Essential Oils by FT-IR Spectroscopy and Partial-Least-Squares Regression. Spectroscopy. 2016;31(8): 26-37.
13. Boughendjioua H, Djeddi S. Fourier Transformed Infrared Spectroscopy Analysis of Constituents of Lemon Essential oils from Algeria. American J Optics Photonics. 2017;5(3):30-35.

14. Luca SV, Głowniak K, Skalicka-Wozniak K. Coumarins: Analytical and Preparative Techniques. John Wiley and Sons, America, 2018.

15. Tangpao T, Chung H, Sommano S. Aromatic Profiles of Essential Oils from Five Commonly Used Thai Basils. Foods. 2018;7(11):175.

16. Foudah AI, Alam P, Alam A, Salkini MA, Alqarni MH, Yusufoglu HS. Development of High-performance Thin-layer Chromatography (HPTLC) Validated Method for Simultaneous quantification of Eucalyptol and $\alpha$-Pinene in Lamiaceae Plants. J Pharm Res Int. 2019;31(6):1-11.

17. Sahayaraja PA, Gowri J, Dharmalingama V, Shobana R, Prema AA. Phytochemical Screening by FTIR Spectroscopic Analysis of Leaf and Stem extracts of Wedelia biflora. Int J Nano Corr Sci Engg. 2015; 2(5):322-334.

18. Tahir MA, Abbasi MSA. FTIR Spectroscopic Analysis of Mentha spicata L. (Garden mint). Asian J Chem Sci. 2020;7(1):1-5.

19. Morar M, Fetea F, Rotar AM, Nagy M, Semeniuc CA. Characterization of Essential oils Extracted from Different Aromatic Plants by FTIR spectroscopy. Bulletin UASVM Food Science and Technology. 2017;74(1):1-2.

20. Geethika K, Sunojkumar P. Phytochemical Screening and HighPerformance Thin-Layer Chromatography Fingerprint Profile of Three Species of Leucas (Lamiaceae). Ancient Sci Life. 2017;37:102-107.

21. Gomathi D, Ravikumar G, Kalaiselvi M, Vidya B, Uma C. HPTLC Fingerprinting Analysis of Evolvulus alsinoides (L.) L. J Acute Med. 2012 2(3):77-82.

22. Iwin C, Varkey, Kasthuri gm. HPTLC Analysis of Stem Bark Extracts of Terminalia chebula Retz. for Alkaloid Profile. Asian J Biochem. 2016;11:97-103.

23. Vinatha B, Kute V, Kuchana V, Shreelekha J, Sreeharshini K, Reddy IA. Phytochemical Screening, HPTLC Fingerprint Analysis of Leaf Extract of Bridelia montana (Roxb) Willd. Int J Pharmacogn Phytochem Res. 2017;9(6):797-800.

24. Bobby MA, Wesely EG, Johnson M. FT-IR Studies on the Leaves of Albizia lebbeck Benth. Int J Pharm Pharm Sci. 2012; 4(3): 293-296.

25. Thangarajan S, Paramasivam R, Chinthamony AR, Palanisamy CP, Velliyur KG. Element and Functional Group Analysis of Ichnocarpus frutescens R. Br. (Apocynaceae). Int J Pharm Pharm Sci. 2012;4(5):343-345.

26. Rao PS, Navinchandra S, Jayaveera KN. HPTLC Analysis of the Essential oil from Pimenta dioica leaf. J Appl Pharm Sci. 2012;2(12):140-148.

27. Srinivasan P, Dineshbabu J, Manimekalai K, Priya DD. Spectroscopic Analysis and Antibacterial Efficacy of Bioactive Compounds from Limonia acidissima L. Fruit Extract Against Clinical Pathogens. Int J Pharm Pharm Sci. 2015;7(3):383-389.

28. Saravana PP, Gopalakrishnan VK. Phytochemical Screening, Functional groups and Elemental Analysis of Leaf Extract of Ipomoea obscura (L) ker-gawl. Int J Pharm Pharm Sci. 2014;6(9):83-89.

29. Sundaram S, Palanisamy CP, Velliyur KG. Chromatographic and Spectrophotometric Analysis of Bioactive Compounds from Cayratia trifolia (L) stem. Int J Pharm Pharm Sci. 2016;8(6):56-64.

30. Jayashree VH, Ramesh $\mathrm{L}$. Isolation and Identification of a Flavone from Fruit pulp of Feronia limonia. Int J Curr Pharm Res. 2014;6(4):28-31.

31. Derwich E, Chabir R, Taouil R, Senhaji O. In vitro Antioxidant Activity and GC-MS Studies on the Leaves of Mentha piperita (Lamiaceae) from Morocco. Int J Pharm Sci Drug Res. 2011;3(2):130-136.

32. Mothana RA, Al-Said MS, Al-Yahya MA, Al-Rehaily AJ, Khaled JM. GC and GC-MS Analysis of Essential oil Composition of the Endemic Soqotraen Leucas virgata Balf.f. and its Antimicrobial and Antioxidant Activities. Int J mol Sci. 2013;14(11):23129-23139. doi: 10.3390/ijms141123129.

33. Joshi RK. GC-MS Analysis of the Essential Oil of Leucas indica from India. Nat Prod Commun. 2014;9(11):1607-1608. doi. org/10.1177/1934578X1400901119.

34. Goudjil MB, Zighmi S, Hamada D, Mahcenec Z, Bencheikhae SE, Ladjel S. Biological Activities of Essential oils Extracted from Thymus 
FTIR and GC fingerprint of Eo from P. benghalensis

capitatus (Lamiaceae) South African. J Bot. 2020;128:274-282. doi. org/10.1016/j.sajb.2019.11.020.

35. Taarit MB, Msaada K, Hosni K, Marzouk B. GC Analyses of Salvia Seeds as Valuable Essential oil Source. Adv Chem. 2014; Article ID 838162: 1-6. doi.org/10.1155/2014/838162.

36. Satyal P, Jones TH, Lopez EM, McFeeters RL, Nasser A, Ali A, et al.
Chemotypic Characterization and Biological Activity of Rosmarinus officinalis. Foods. 2017;6(20):1-15. doi:10.3390/foods6030020.

37. Kariminik A, Moradalizadeh M, Foroughi mm, Tebyanian $\mathrm{H}$, Motaghi mm. Chemical Composition and Antibacterial Activity of the Essential oils Extracted from 4 Medicinal Plants (Labiatae) of Kerman. Iran J Appl Biotechnol Rep. 2019;6(4):172-179.

HOW TO CITE THIS ARTICLE: Premakumari PD, Sarayu MG, Kumaraswamy M. Fourier transform infrared and chromatographic fingerprint of essential oil from Pogostemon benghalensis (Burm. F.) Kuntze. Int. J. Pharm. Sci. Drug Res. 2020;12(5):480-487. D0I: 10.25004/IJPSDR.2020.120508 